\title{
In-Class Manufacturing Simulation: A Hands On Approach
}

Arthur Hintz, St. John Fisher College

Michael Fedoryshyn, St. John Fisher College

\begin{abstract}
Many suggestions on ways to improve accounting education have been presented by professional and academic organizations. These studies are critical of current accounting education for being too focused on the transfer of information from faculty member to student (PricewaterhouseCoopers, 2003), failing to involve students as active participants in the learning process (AECC, 1990), and reinforcing student perception that accounting is boring and uninspiring (Cohen and Hanno, 1993). To address these concerns we developed an in-class simulation of a manufacturing environment that introduces students to the terminology and processes found in a typical manufacturing environment. The simulation requires students to work in teams to be the low cost manufacturer of the product, in this case paper airplanes, and to deal with real situations that are typically encountered by many manufacturers. Students are active participants in the process and are able to compare their teams' performance against the performance of their classmates. Students indicate this exercise is interesting, informative, fun and a welcome change from the normal lecture format. Faculty members have also found the exercise a refreshing break from the normal lecture, especially since students are enthusiastic and interested participants.
\end{abstract}

\section{INTRODUCTION}

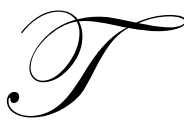

he Accounting Education Change Commission (AECC) report on improving accounting education concluded, "Students should be active participants in the learning process instead of passive recipients of information" (AECC, 1990). The AECC report also indicated that more emphasis should be placed on "learning by doing" and encouraged educators to increase opportunities for students to work collaboratively. Other recent studies have indicated that accounting pedagogy should include some elements of group work and role playing (Albrecht \& Sack, 2000).

A recent position statement on accounting education by PricewaterhouseCoopers (PWC) noted that many universities are evolving from a traditional curriculum based on "information transfer" to one based on "collaborative learning among teachers and peers that encourages the joint generation of knowledge and understanding... such that both faculty and students are engaged in two way interactions that encourage joint generation of knowledge and understanding" (PWC, 2003).

The PricewaterhouseCoopers position statement also noted that the first courses in Accounting markets the discipline to potential future majors and "The first course must be among the most highly rated and desirable courses on campus". However, making the first course in accounting attractive to students requires faculty members to overcome student perceptions that the study of accounting is boring (Cohen \& Hanno, 1997).

To overcome students' perception that the study of accounting is boring and to actively engage students and faculty in the learning process we developed a hands-on simulation of a manufacturing environment based on a concept originally presented in the Accounting Educators Report (Swain, 1997) and which is expanded on in this paper. Student feedback indicates they feel the simulation is informative, interesting, exciting and fun. 


\section{SIMULATION OVERVIEW}

One of the problems teaching managerial accounting concepts is that many students have no experience working in a manufacturing environment. To overcome this lack of perspective, instructors might schedule a trip to a local manufacturing location and ask the controller to describe the manufacturing process and the applicable accounting. This approach is difficult and sometimes unworkable for a number of reasons. First, the logistics involved in trying to find a time outside the normal class period when all students can participate is difficult. Second, many manufacturing environments are complex and students may come away more confused than before the trip.

This simulation is a controlled, in-class exercise which simplifies the process and which can be done during regularly scheduled class time. The simulation introduces students to a job order manufacturing environment and some problems and decisions managers face every day. Students are introduced to basic cost terminology in an interesting and easy to understand format that provides a welcome change from normal lectures for both the students and the instructor. Students are active participants, work in teams and deal with real situations that might be encountered in a manufacturing environment.

During the manufacturing process competing teams are asked to produce paper airplanes as efficiently and cost effectively as possible. At the conclusion of the manufacturing simulation results are compared between teams, the performance of each team is evaluated and reasons for the variance in cost per airplane among the teams is discussed.

Paper airplanes were chosen because the manufacturing process is easy to setup and explain and the cost of materials is relatively inexpensive. The instructor is able to introduce as many complexities as desired into the simulation to meet the skill level of the students. The only constraints are the class time devoted to the project and the imagination and creativity of the instructor.

This project is appropriate for any level course as an introduction to the terminology of cost accounting and as an overview to the flow of costs through a manufacturing environment. The model can be adapted to an introductory course in managerial accounting, a cost accounting course or even a graduate level MBA course.

Depending on the number of minutes for each class period the simulation can be done in one class session or spread out over two classes. A typical simulation will take approximately 85 to 125 minutes with the time allocated as follows:

$\begin{aligned} 10-15 \text { minutes } & \text { Assign responsibilities and review the rules and instructions } \\ 5-10 \text { minutes } & \text { Demonstrate proper production technique and provide training } \\ 35-45 \text { minutes } & \text { Produce the product } \\ 5-10 \text { minutes } & \text { Reconcile results } \\ 10-15 \text { minutes } & \text { Summarize and compare results for each team } \\ 15-20 \text { minutes } & \text { Discuss results } \\ 5-10 \text { minutes } & \text { Reward performance (Optional) }\end{aligned}$

There is no limit on the number of students that can participate, simply create more or less teams depending on the class size. The simulation works best if there are at least three teams involved so that variation in results occurs.

\section{PRE-SIMULATION ORGANIZATION}

Prior to the class when the simulation will be conducted, the instructor will need to assemble the following materials. These materials are sufficient for a class size of up to 40 students, for a larger class size the materials should be increased accordingly. 


\section{Sheets Of Paper}

The number of sheets of paper that should be available at the start of the simulation is:

- $\quad 200$ sheets - White $8 \frac{1}{1 / 2} \times 11$ paper

- $\quad 30$ sheets - Blue $8 \frac{1}{1} 2 \times 11$ paper

- 10 sheets - White $11 \times 14$ paper

\section{Order Entry Cards}

A list of orders that teams produce during the simulation is included as Exhibit 1.

These orders are written on 3 X 5 index cards and can be modified to increase or decrease the complexity of the simulation. For a larger class additional orders can be created or the number of planes produced in each order can be increased.

\section{Play Money}

Each production team is given $\$ 150$ of play money for use during the simulation so sufficient packets of money should be available for the estimated number of teams.

\section{SIMULATION SETUP}

\section{Assigning Responsibilities}

Depending on the class, the instructor can assign students to the various positions or let students volunteer for their position. Everyone participates in some function and positions are generally filled in the following order.

Plant Manager. The instructor may want to act as the Plant Manger in the simulation or let a student play the role. The Plant Manger is responsible for making all decisions or resolving any problems that come up during the simulation. Typical decisions might be whether the product meets quality specifications or what to do if a supervisor wants to replace one of their workers. At the end of the simulation the Plant Manger may be asked to evaluate performance and assign rewards, although this is an optional part of the simulation.

Production Supervisors. The most important role in the simulation is the Production Supervisor. The Production Supervisors are responsible for training and supervising the production workers and making sure the work proceeds in an organized and efficient manner.

Controllers. Each team is assigned a Controller who is responsible for keeping track of the money spent by their team during the simulation. The Controller is given $\$ 150$ of play money at the beginning of the simulation and needs to record whether the money is spent for direct material, direct labor, order entry costs or other factory overhead costs.

Quality Control Clerk. A Quality Control Clerk can be assigned to each team or a team of 2-3 students could provide this function for all the teams. The Quality Control Clerk's responsibility is to check the finished product to make sure it conforms to specifications and to randomly fly a few of the airplanes to make sure they perform in an acceptable manner. Quality Control Clerks are instructed not to be too rigid in the evaluation of quality; otherwise all the time would be spent producing just a few orders. However, some rejected airplanes provide good learning opportunities for the production teams.

Order Entry Clerk. The Order Entry Clerk is responsible for handing out the order cards and collecting the order entry cost of $\$ 1$ per order. While not a difficult position, students find this job interesting since they get a 
chance to see all the various types of problems that teams will be asked to contend with during the manufacturing process.

Material Control Clerk. These persons are responsible for issuing the raw material to the production teams so the product can be manufactured. They need collect the correct amount of money from the teams for the material issued and at the end will need to reconcile the amount of material used with the amount of money collected.

Finished Goods Clerk. These persons are responsible for collecting the finished product after it leaves the production area and recording how many completed airplanes each team produces. In order to accurately calculate the cost/airplane at the end of the simulation it is important to get an accurate count of the production by each team.

Production Workers. Any remaining students are randomly assigned to the Production Supervisors as the production workers. It works best with 3-4 workers per team so some advance planning is necessary to estimate the correct number of teams that need to be created.

A sample layout of the production area and the various responsibilities is shown as Exhibit 2 and can be adjusted to fit the configuration of the classroom.

\section{Rules And Instructions}

Once the responsibilities are assigned and production teams are in place the following list of Rules and Instructions is read to the students. The Rules and Instructions are also shown in Exhibit 3.

1. To begin production, the Production Supervisor must get an order entry card from the Order Entry Clerk. The cost is $\$ 1$ per order.

2. The Supervisor must read the order card to his production team before starting the order. The order card will specify A) the number of airplanes to be produced, B) the symbol that needs to be written anywhere on one of the wings of the airplane and C) any other special instructions or directions that need to be followed.

3. Only the Production Workers may work on the airplanes.

4. Each team must successfully complete an order and deliver it to the Finished Goods Clerk before starting the next order.

5. Only the Production Supervisor may obtain paper from the Material Control Clerk and deliver the order from Quality Control to Finished Goods.

6. The cost for material is as follows:

- $\quad \$ 1 /$ sheet - White $8 \frac{1}{2} 2 \times 11$ paper

- $\$ 2 /$ sheet - Blue $8 \frac{1}{2} \times 11$ paper

- $\$ 2 /$ sheet - White $11 \times 14$ paper

7. If an airplane is rejected by Quality Control or damaged during the manufacturing process a new piece of paper must be used to produce the airplane.

8. All questions and concerns should be directed to the Plant Manager for resolution.

9. At the end of the simulation, each team will need to pay their production workers a wage for the time they spent producing the airplanes. (Note: Either establish a rate of $\$ 5 /$ worker or leave it up to each team to determine their appropriate rate).

10. Each team will pay the Plant Manager $\$ 20$ to cover all the other costs of running the Factory (indirect labor, utilities, rent, etc.).

11. The Controller of each team has $\$ 150$ of play money and is responsible for keeping track of how much money is spent for the following:

- Order entry costs

- Direct Material costs

- Direct Labor costs

- All other Factory Overhead costs 


\section{Demonstration Of The Proper Manufacturing Technique}

Every student recalls from their childhood a different method of producing paper airplanes. In order to be consistent in the manufacturing process the instructor should show students the "approved" method of producing airplanes and give each Production Supervisor some blank sheets of paper so they can train each of their production workers on the proper technique. Teams are not charged for this paper and the practice planes should be discarded before beginning the actual production.

\section{PRODUCTION}

Once all the teams are organized and trained and the students are in their respective positions, manufacturing begins and teams produce airplanes for 35-45 minutes. Teams typically start off slowly as they learn the process but pick up speed as they become comfortable with the manufacturing process. The Plant Manger should be actively engaged in the production environment ensuring that teams are functioning correctly and answering any questions that arise.

The simulation is set up so the first order each team receives is easy to produce and does not have any complexities. Later orders present the teams with various challenges and roadblocks that they have to overcome and which result in variations in the cost per airplane.

\section{RESULTS}

\section{Reconciling Results}

Once the simulation is completed, certain functions are asked to summarize and reconcile their results.

Material Control Clerk. The Material Control persons are asked to count both the money collected and the remaining sheets of paper. They calculate the amount of paper used in the various colors and sizes and should reconcile the amount of money collected with the amount of paper issued.

Order Entry Clerk. The Order Entry persons are asked to verify they have collected $\$ 1$ for each of the order cards given out.

Controllers. The Controllers count the money they have left and account for the money spent during the course of the simulation.

Finished Goods Clerk. These people need to account for all the planes that have been completed by the teams during the course of the simulation.

\section{Summarizing And Discussing Results}

After the results are reconciled, the instructor can summarize the results for each team. A sample summary sheet that can be used for this purpose is included as Exhibit 4.

The production cost per airplane will typically vary by $50 \%$ or more from the low cost producer to the high cost producer. The wide variation in performance occurs because of the way the orders have been designed. One of the orders is always a high volume order, produced on standard $81 / 2 \mathrm{X} 11$ white paper, with few symbols required. The team that gets this order is usually the low cost producer. The teams get the non-standard orders produced on the blue paper or the $11 \times 14$ paper are almost always the high cost producers because the paper for these planes costs twice the standard white, $81 \frac{1}{2}$ X 11 paper. 
Luck and not the effectiveness of the supervisor or the efficiency of the workers generally determines the outcome of the simulation. However, when results are discussed with the class, students are asked to play along with the discussion and not focus on luck to explain the results.

The interesting and unpredictable part of the exercise comes when discussing the results of the simulation since discussion of the results is at the direction and guidance of the instructor. Generally it is best to start the discussion with the Production Supervisor of the high cost producing team to try and identify causes for their cost problem. The Supervisor is asked what they would, or could, do differently in the future. The discussion always includes ideas to move production to lower cost areas of the world, invest in new technologies to reduce labor content, improve the efficiencies of the workers by better training, specialize the workers functions or terminate poor performing workers. The discussion typically ends with the high cost producers being asked what will happen in the long run if they continue to remain the high cost producer.

Discussion time is also focused on the low cost producers and why they did so well. Many times they attribute the success to their own individual efforts and feel that they should be sufficiently rewarded by larger salary increases or bonuses or a better grade in the course.

The impact that special orders have on manufacturing costs is discussed, as well as other factors that typically cause tensions between manufacturing and marketing. per unit.

Finally, students should understand the relationship between fixed costs, production volume and the cost

\section{REWARDING PERFORMANCE}

As an optional step in the simulation the Plant Manger can be asked to assess the performance of the employees in his factory. In past simulations, the Plant Manager has been supplied with appropriate rewards (lottery tickets, college pens, etc.) and asked to distribute these as they deem appropriate. As the Plant Manager distributes the rewards they are asked to indicate on what basis the reward is being given. Past experience shows that the Plant Mangers have elected to distribute the rewards in a variety of different manners and for a variety of reasons.

After the rewards are distributed, students who received the rewards are asked how they felt and also some of the other students who did not receive the rewards are asked how they felt. The discussions generally highlight some of the benefits and risks of a merit based reward and incentive system.

\section{CONCLUSION}

The simulation is an effective method for teaching basic managerial or cost accounting concepts. It involves students as active participants in the process and allows them to work collaboratively to solve problems typically encountered in real world manufacturing environments. Students and faculty members find the simulation interesting, informative and fun and a welcome change from the traditional lecture format.

\section{REFERENCES}

1. Accounting Education Change Commission (AECC). 1990. Objectives of education for accountants: Position statement number one. Issues in Accounting Education (Fall): 307-312.

2. Albrecht, W., and R. Sack. 2000. Accounting Education. Charting the Course through a Perilous Future. Sarasota, Fl.: American Accounting Association.

3. Cohen, J., \& Hanno, D.M. 1993. An analysis of underlying constructs affecting the choice of accounting as a major. Issues in Accounting Education. 8(2). 219-238.

4. PricewaterhouseCoopers. 2003. Educating for the Public Trust. The PricewaterhouseCoopers Position on Accounting Education. New York, NY.

5. Swain, M. 1997. Paper Airplanes and Process Costing: A Teaching Note. Accounting Instructors' Report (Fall): 3-4. 


\section{EXHIBIT 1}

SAMPLE ORDERS

\begin{tabular}{|c|c|c|c|}
\hline $\begin{array}{c}\text { Order } \\
\text { Number }\end{array}$ & $\begin{array}{l}\text { Quantity } \\
\text { Of Planes } \\
\text { To Produce } \\
\end{array}$ & $\begin{array}{l}\text { Symbol } \\
\text { To Put } \\
\text { On Wing }\end{array}$ & Special Instructions \\
\hline 1 & 4 & $*+* *$ & \\
\hline 2 & 5 & $* * *$ & \\
\hline 3 & 6 & $*+++*$ & $\begin{array}{l}\text { This order requires blue paper, which costs } \$ 2 / \text { sheet, because it is } \\
\text { purchased in small quantities. }\end{array}$ \\
\hline 4 & 8 & $+++*$ & \\
\hline 5 & 5 & $+++* * * *$ & Two workers called in sick and cannot work on this order. \\
\hline 6 & 20 & $*_{+}$ & \\
\hline 7 & 1 & & $\begin{array}{l}\text { Write the names and birth dates of each worker and their siblings on } \\
\text { the wing. }\end{array}$ \\
\hline 8 & 4 & $*+* *_{+}^{*}+$ & $\begin{array}{l}\text { Production workers take too long on breaks. The entire team must } \\
\text { go to the vending machines and get a coffee for the Plant Manager. }\end{array}$ \\
\hline 9 & 5 & $* * *$ & $\begin{array}{l}\text { Your marketing people sold a non-standard size, so these planes are } \\
\text { to be built on } 11 \times 14 \text { paper. Since the paper is non-standard, } \\
\text { Inventory Control must place a rush order so the paper costs } \\
\$ 2 / \text { sheet. }\end{array}$ \\
\hline 10 & 3 & & $\begin{array}{l}\text { This is a very special order for the U.S. government. The Pledge of } \\
\text { Allegiance must be written on the wing. }\end{array}$ \\
\hline 11 & 6 & $* *++$ & $\begin{array}{l}\text { Your production equipment was not well maintained. You must } \\
\text { produce this order with one hand. The other hand must be behind } \\
\text { your back. }\end{array}$ \\
\hline 12 & 12 & $* *$ & $\begin{array}{l}\text { Produce four planes on white } 81 / 2 \times 11 \text { paper, four planes on blue } \\
\text { paper, and four planes on } 11 \times 14 \text { paper. }\end{array}$ \\
\hline 13 & 6 & $* * *++*$ & $\begin{array}{l}\text { This order requires blue paper, which costs } \$ 2 / \text { sheet, because it is } \\
\text { purchased in small quantities. }\end{array}$ \\
\hline 14 & 3 & $* *+++$ & $\begin{array}{l}\text { Promote one of your production works to Finished Goods Clerk. } \\
\text { The Finished Goods Clerk goes to production. }\end{array}$ \\
\hline 15 & 4 & $++* *++$ & $\begin{array}{l}\text { Your workers are poorly supervised. Send each team member to } \\
\text { the appropriate restroom to pick up a paper towel before beginning } \\
\text { the order. }\end{array}$ \\
\hline 16 & 5 & 16 *'s then 30 +'s. & \\
\hline 17 & 4 & $++* * * *$ & $\begin{array}{l}\text { Your factory burned down. You must wait three minutes before } \\
\text { beginning production. }\end{array}$ \\
\hline 18 & 4 & $+* *+$ & \\
\hline 19 & 4 & ++++++ & $\begin{array}{l}\text { Your union is on strike. Workers cannot work for two minutes } \\
\text { before beginning production. }\end{array}$ \\
\hline 20 & 6 & $* * *+$ & $\begin{array}{l}\text { Your production workers celebrated the Lakers NBA Championship } \\
\text { at lunch and came back under the weather. They must produce the } \\
\text { order with their hands behind their backs. }\end{array}$ \\
\hline 21 & 1 & $* * *+++* *++*+$ & \\
\hline 22 & 8 & $++* * *+$ & $\begin{array}{l}\text { The first, middle and last name of the production worker whose } \\
\text { birthday is closest to the Plant Managers' has to be printed on the } \\
\text { wing. }\end{array}$ \\
\hline 23 & 5 & $* *+++$ & $\begin{array}{l}\text { This order requires blue paper, which costs } \$ 2 / \text { sheet, because it is } \\
\text { purchased in small quantities. }\end{array}$ \\
\hline
\end{tabular}




\section{EXHIBIT 2}

CLASSROOM LAYOUT AND RESPONSIBILITIES

PLANT MANAGER

1 PERSON

TEAM 1

SUPERVISOR 1 PERSON

CONTROLLER

1 PERSON

PRODUCTION

WORKERS

3 - 5 PERSONS

QUALITY CONTROL

CLERK

1 PERSON
TEAM 2

SUPERVISOR

1 PERSON

CONTROLLER

1 PERSON

PRODUCTION

WORKERS

3 - 5 PERSONS

QUALITY CONTROL

CLERK

1 PERSON
TEAM 3

SUPERVISOR 1 PERSON

CONTROLLER 1 PERSON

PRODUCTION

WORKERS

3 - 5 PERSONS

QUALITY CONTROL CLERK

1 PERSON

SUPPORT POSITIONS

FINISHED GOODS

CLERK

1-3 PERSONS
MATERIAL CONTROL

CLERK

1-2 PERSONS
ORDER ENTRY

CLERK

1-2 PERSONS 


\section{EXHIBIT 3 \\ RULES AND INSTRUCTIONS}

1. To begin production, the Production Supervisor must get an order entry card from the Order Entry Clerk. The cost is $\$ 1$ per order.

2. The Supervisor must read the order card to his production team before starting the order. The order card will specify A) the number of airplanes to be produced, B) the symbol that needs to be written anywhere on one of the wings of the airplane and C) any other special instructions or directions that need to be followed.

3. Only the Production Workers may work on the airplanes.

4. Each team must successfully complete an order and deliver it to the Finished Goods Clerk before starting the next order.

5. Only the Production Supervisor may obtain paper from the Material Control Clerk and deliver the order from Quality Control to Finished Goods.

6. The cost for material is as follows:

- $\quad \$ 1 /$ sheet - White $81 / 2 \times 11$ paper

- $\$ 2 /$ sheet - Blue $8 \frac{1}{2} \times 11$ paper

- $\$ 2 /$ sheet - White $11 \times 14$ paper

7. If an airplane is rejected by Quality Control or damaged during the manufacturing process a new piece of paper must be used to produce the airplane.

8. All questions and concerns should be directed to the Plant Manager for resolution.

9. At the end of the simulation, each team will need to pay their production workers a wage for the time they spent producing the airplanes. (Note: Either establish a rate of $\$ 5 /$ worker or leave it up to each team to determine their appropriate rate).

10. Each team will pay the Plant Manager $\$ 20$ to cover all the other costs of running the Factory (indirect labor, utilities, rent, etc.).

11. The Controller of each team has $\$ 150$ of play money and is responsible for keeping track of how much money is spent for the following:

- Order entry costs

- Direct Material costs

- Direct Labor costs

- All other Factory Overhead costs

EXHIBIT 4

SUMMARY RESULTS WORKSHEET

$\underline{\text { TEAM } 1}$ TEAM 2

\$ Of Order Entry Costs

\$ Of Material

\$ Direct Labor

\$ Of Factory Overhead

Total Manufacturing Costs

Divided By: \# Airplanes Produced

$=$ Cost/Airplane 
NOTES 